\title{
Rhinoskopischer Befund bei einem knackenden Geräusch im 0hr.
}

\author{
Von \\ Dr. O. Boeck \\ in Magdeburg.
}

Im März v. Jhr. stellte Herr College Dr. Sendler in der hiesigen medizinischen Gesellschaft einen 20jährigen Kaufmann P... vor, der über ein eigenthümliches Geräusch im linken $\mathrm{Ohr}$ zu klagen hatte. Dasselbe war analog dem, das Joh, Miiller von einer Contraction des Tensor tympani ableitete und erst vor wenigen Jahren durch Politzer und gleichzeitig ron Luschka als an der Gaumenmündung der Tuba Eustachii entstanden erklärt wurde. Es hatte grosse Aehnlichkeit mit dem Geräusch, das entsteht, wenn man bei geschlossenem Munde etwas Speichel zwischen Lippen und Zähne bringt und nun geringe Saugbewegungen macht. - Der betreffende Patient sagte aus, dass er dieses Geräusch schon so lange er denken könne im Ohre verspüre, dass es mitunter wohl auf Stunden und Tage verschwinde, aber oft, namentlich Nachts so stark auftrete, dass er dadureh erwache und nicht wieder einschlafen könne. Schwerhörend sei er auf diesem Ohre nicht, während ex aut dem andern, wo kein Geräusch vorhanden, nicht ganz scharf höre.

Herr Dr. Sendler war so freundlich mir den Patienten zur weiteren Untersuchung und Behandlung au überlassen und ich habe dabei Folgendes gefunden: Das Geräusch ist isochronisch mit dem Pulse; 
geht derselbe langsam, so ist auch das Geräusch langsamer und umgekehrt. Es setzt mitunter $1 / 2-1$ Minute und darüber aus, um alsdann wiederzukommen; doch ist die Zahl der aufeinanderfolgenden Geräusche nicht dieselbe d. L. mitunter entstehen nur 3 Geräusche hintereinander, mitunter 70 und mehr. Wovon die längere Dauer der oinzelnen Intervalle abhängig, ist nicht nachzuweisen. Gleichzeitig mit dem Knacken im Ohre, das man sehr gut entweder durch Auflegen des Ohres oder durch das Otoscop hören kann, hebt sich beständig der. Kehlkopf und ebenso wird der Winkel, den der Boden der Mundhöhle mit dem Halse bildet, fortwährend grösser und kleiner. Man konnte demnach aus den Hebungen und Senkungen des Kehlkopfes, die vielleicht 2-3 Millim. betrugen, die Schnelligkeit der Herzcontractionen zählen. Beim Oeffnen des Mundes sah man deutlich (und dies haben ebenso wie die Bewegungen des Kellkopfes Mehrere der hiesigen Herrn Kollegen gesehen) beständige Hebungen und Senkungen des Gaumensegels und zwar ganz gleichzeitig mit dem Geräusch im Ohr und folglich auch isochroniseh mit dem Pulse. War eine Pause im Geräusch eingetreten, so konnte man dasselbe ein mal durch eine Schluckbewegung hervorrufen. Die Hörweite für meine auf $5^{\prime}$ hörbare Taschenuhr war links normal, ebenso für den थ. Conta'schen Versuch; rechts betrug sie nur 5-6" und war auch für die Sprache vermindert. Bei der Inspection des Trommelfells war links ausser einer unbedeutenden Trübung im hintern Segmente Nichts Auffälliges zu bemerken: der Glanz und der Lichtkegel waren normal, Proc. brevis und Hammergriff boten Nichts Anssergewöbnliches dar, die Hammergriffgefässe waren nicht gefüllt, die Wölbung des Trommelfells nicht übermässig ausgesprochen. Während ich deutlich die Hebungen und Senkungen des Kehlkopfes sah, und der Kranke angab, dass or das Geräusch im Ohre empfinde, konnte ich auch nicht die geringste Veränderung in den Wölbungsverhältnissen des Trommelfells und der Lage des Hammergriffs nachweisen. Ich führe das um desshalb ausdrücklich an, weil Schwartze auf pag $4 \mathrm{~d}$. Bd. einen ziemlich ähnlichen Fall veröffentlicht hat, in weichen mit dem Geräusch isochronisch die Inspection einen klonischen Krampf des Tensor tympani zeigte. Rechts war im Gehörgange Eiter angesammelt, nach dessen Entfernung sich das Trommelfell zum grössten Theile perforirt zeigte, Hammergriff fehlend, dagegen Proc. brevis vorhanden und am hintern untern Theile der sichtbaren Labyrinthwand Granulationen, die ich nach und nach mit Lapis infern. zerstörte.

Interessant war nun der rhinoskopische Befund, der sich mir darbot. Da das Gaumensegel ziemlich schlaff herunterhing und durch 
die Contractionen nur circ. $1 \mathrm{Mm}$. in die Höhe gezogen wurde, die hintere Rachenwand auch ziemlich wenig- empfindlich, so war ein kleiner Kehlkopfspiegel leicht einzuführen. Zuerst fiel mir die bedeutende Schwellung und Röthung der. Schleimhaut des hintern Nașenraumes auf, besonders verglichen mit der Schleimhaut des Rachens, die . ich fuir ganz normal ansah; die. Schleimhaut der, Chomnen war'stark gewulstet und mit angetrocknetem Secret bedeckt und ebenso stark waren' die Lippen der linken Tuba geschwellt; anf ihnen zäher Sehleim aufgelagert, dabei stark geröthet und, yor. Allem machte sich an der vorderen Lippe eine stark erweiterte und hyperämische Vene bemerkbar. Die Betrachtung derselben erleichterte mir auch hauptsächlich die folgende Beobachtung: Es wurde nämlich gan: isochronisch mit den Bewegungen des Kehlkopfes und der Gaumenklappe die vordere Lippe von der hinteren abgezogen und wieder an dieselbe gerïckt. Hörte das Knacken im Ohr auf, so standen auch die Lippen der Tuba still. Ich will übrigens nicht verschweigen, dass mir noch jetzt unerklärlich ist, durch welche Ursache jene klonischen Contractionen der verschiedenen Muskelgruppen isochronisch mit dem Pulse hervorgerufen worden sind. Am Herzen war durch die Auscultation keine pathologische Veränderung nachzuweisen und auch das übrige Befinden des Patienten sprach gegen solche Annahme.

Dieser Fall bestätigt nun auch, wie ich glaube, durch die Rhinoskopie die von Politzer aufgestellte Hypothese (Wiener MedizinalHalle Nr. 18. 1862 und Bd. I. pag. 5 dieses Archives), dass das ron Joh. Miller für eine Contraction des Tensor tympani angesehene entotische Geräusch auf einem Abziehen der vordern Wand der Tuba von der hinteren beruht und nur durch Täusehung in die Pankenhöhle verlegt wird. Ich will auch noch anführen, dass Funcke (Lehrbuch der Physiolog. Band II. pag. 113 2te Aufl.) vermuthet, das Knacken entstände durch plötzliche Trennung der Gelenkflächen zwischen Hammer und Ambos so wie z. B. beim plötzlichen Dehnen eines Fingers im Gelenk ein knackendes Geräusch entsteht. Es müsste dann ja aber bei jeder Luftdouche dieses Geräusch entstehen, was doch nicht der Fall ist, da dadurch das Trommelfell und mit ihm der Hammer nach aussen gerïckt wird.

Was das weitere Schicksal des obigen Patienten betrifft, so wandte ich des Versuches wegen den inducirten Strom an. Ich setzte die eine Electrode auf den Processus mastoidens, die andere auf die Muskeln, die vom Zungenbein zum Kehlkopf herabgehn. Der Erfolg war, dass bereits nach der 3ten Sitzung die klonischen Krämpfe in 
206 BOECK: Rhinoskopischer Befund bei einem knack. Geräusch in $\mathrm{Ohr}$.

den bezeichneten Muskelgruppen gänzlich aufgehört hatten und $\mathrm{Pa}$ tient das Knacken nur noch dann im Ohr verspiüte, wenn er eine Schluckbewegung machte. (Uebrigens hört man dies, wie ich mich später überzeugte, in geringem Grade beim Schlucken bei den meisten Menschen.)

Ich habe alsdann noch don Catheterismus in Anwendung geaogen und Gurgelungen mit Alaun vornehmen lassen, aber bis Endë Juli, wo ich Patient zum letzten Male sah, bestand jenes Geräusch beim Schlucken noch immer fort. 